School of Finance

University of St.Gallen

FRAGMENTATION IN EUROPEAN EQUITY MARKETS AND MARKET QUALITY - EVIDENCE FROM THE ANALYSIS OF TRADE-THROUGHS

AleXANDer KoHler

RICO VON WYSS

WORKING PAPERS ON FINANCE No. 2012/10

SWISS INSTITUTE OF BANKING AND FINANCE (S/BF - HSG)

OCTOBER 2012 


\title{
Fragmentation in European Equity Markets and Market Quality - Evidence from the Analysis of Trade-Throughs
}

\author{
Alexander Kohler* and Rico von Wyss**
}

January 20, 2012

\begin{abstract}
The implementation of MiFID has lead to a fragmentation of liquidity in European equity trading. We analyze the long-term effects of MiFID on liquidity with a new sample of Swiss stocks and do not find evidence for a worsening of market quality. In contrast, spread and depth measures indicate a general increase in market quality. Given the non-existence of a consolidated tape in Europe, we examine whether trade-throughs prevent the emergence of a virtually consolidated market. We find evidence that trade-throughs originate from informed traders with a priority of execution speed over price and conclude that the occurrence of trade-throughs does not indicate an inferior market quality.
\end{abstract}

Keywords: MiFID, MTF, Market Quality, Trade-Through. JEL Classification: G14, G18.

*Algofin AG, Webergasse 15, 9000 St. Gallen, Switzerland. (corresponding author)

Tel.: +41-71-5350500

Fax: $+41-71-5350501$

E-mail: alexander.kohler@algofin.ch

${ }^{* *}$ University of St. Gallen, Rosenbergstrasse 52, 9000 St. Gallen, Switzerland.

Email: heinrich.vonwyss@unisg.ch

We are grateful to Thomson Reuters for providing data. We also thank Yakov Amihud and the participants of the 2010 Topics in Finance seminar for insightful comments. 


\section{Introduction}

The Markets in Financial Instruments Directive (MiFID) was adopted by the European Parliament and Council in 2004. Aim of the initiative is the protection of investors and the promotion of fair, transparent and efficient financial markets ${ }^{1}$. MiFID had to be implemented by all member countries of the European Union by November 2007. The new regulation replaced a directive of 1993 on investment services in the securities field ${ }^{2}$, which included a concentration rule ${ }^{3}$ that allowed member countries to require the execution of certain orders at a regulated market. Therefore, the concentration rule was beneficial for established national exchanges.

By removing the concentration rule, MiFID enabled the competition among trading venues, which lead to the emergence of alternative trading platforms and their gain of market share. A similar development took place in the United States over the last decade, where $\mathrm{ECNs}^{4}$ like Archipelago, Island and Instinet could increase their market share in the trading of U.S. stocks on the cost of established exchanges like the NYSE and NASDAQ. As a consequence, a consolidation on the level of exchanges took place with the purchase of the ECN Island by Instinet in 2002, the merger of NYSE with Archipelago to the NYSE Group and the purchase of Instinet by NASDAQ in 2005 .

In the course of the implementation of MiFID several multilateral trad-

\footnotetext{
${ }^{1}$ See Council Directive 2004/39/EC of 21 April 2004 on markets in financial instruments, EC (2004).

${ }^{2}$ See Council Directive 93/22/EEC of 10 May 1993 on investment services in the securities field, ECC (1993).

${ }^{3}$ See Art. $14(3)$ of the directive.

${ }^{4}$ Electronic Communication Networks (ECNs) are alternative trading platforms.
} 
ing facilities (MTFs) were launched in Europe ${ }^{5}$, starting in March 2007 with Chi-X, a pan-european MTF owned by a consortium of global financial institutions $^{6}$. In 2008 several MTFs followed like BATS Europe and Nasdaq OMX Europe, two European subsidiaries of American exchanges and Turquoise, an MTF owned by nine investment banks ${ }^{7}$. The increasing number of trading platforms and the possibility, as well as the pressure to choose the most efficient trading channel lead to a fragmentation of trading volume. In June 2010 more than $25 \%$ of the overall trading volume for European equities was traded on four MTFs ${ }^{8}$.

Swiss stocks encountered the same development without regulatory pressure. ${ }^{9}$ According to the Fidessa Fragmentation Index ${ }^{10}$ about $75 \%$ of the aggregated trading volume of the SMI stocks in June 2008 was traded on the Swiss exchange and about $1.3 \%$ on Chi-X (the rest was traded on dark venues, OTC and through systematic internalisers). In June 2009 the share of the Swiss exchange had dropped to $65 \%$ and in June 2010 to $51 \%$ of the overall trading volume. The share of Chi-X has risen to almost $13 \%$ and other MTFs could increase their market share as well (BATS Europe accounts for almost 6\%, Turquoise for almost 3\%, Nyse Arca and Nasdaq Europe together

\footnotetext{
${ }^{5}$ See Gresse (2010) for a detailed timetable of the development of MTFs in Europe.

${ }^{6}$ See www.chi-x.com.

${ }^{7}$ See www.tradeturquoise.com

${ }^{8}$ According to the Equity Market Share Report for June 2010 of Thomson Reuters, the fraction of the aggregated trading volume in June 2010 of Chi-X, Nasdaq OMX Nordic, BATS Europe and Turquoise equals 26.9\%. The report includes on-exchange and MTF reported trading volume.

${ }^{9}$ The implementation of MiFID is only mandatory for companies in the European Economic Area (EEA) but the emergence of additional trading platforms like MTFs has also affected the trading of Swiss stocks, as they are also traded on these platforms.

${ }^{10}$ The Fidessa Fragmentation Index is a measure for the concentration of trading in one market vs. the fragmentation of trading across different trading venues. For more information we refer to fragmentation.fidessa.com.
} 
for $0.5 \%$ ).

In this article we analyze several questions around liquidity fragmentation in Europe. How is market quality in Europe as a whole affected by fragmentation? Are the effects similar for large and mid caps or do we observe differences related to company size? Do we observe a similar development as in the United States or does the lack of a trade-through prohibition prevent the emergence of a virtual consolidated market as discussed by Hendershott \& Jones (2005) and O'Hara \& Ye (2011) and, therefore, deteriorate market quality? To address these questions, we analyze measures of liquidity fragmentation and market quality with a new sample covering intraday data from the Swiss stock exchange and three MTFs for 29 Swiss stocks between November 3, 2008 and June 30, 2010.

We contribute to the literature on the effects of liquidity fragmentation in Europe in three important aspects. First, our study helps to understand the effects of liquidity fragmentation in the European equities markets. Although a number of studies analyzed liquidity fragmentation in U.S. markets, there is a gap in the analysis of long-term effects of the implementation of MiFID and the related fragmentation of liquidity for European stocks. Second, we concentrate on institutional differences between U.S. and European equities markets by the analysis of trade-throughs. In Europe there is neither a consolidated tape nor a rule prohibiting trade-throughs. But still literature analyzing these differences is insufficient. Hendershott \& Jones (2005) analyze the relaxation of the trade-through prohibition for the three most active ETFs in the U.S. market and its effects on market quality. Although they find no evidence for negative effects on market quality, they conclude that 
this could be related to the high liquidity of the ETFs analyzed. Our study is related to Storkenmaier \& Wagener (2011) who analyze quote quality and trade-throughs for a sample of UK blue-chip stocks. However, our contribution is to provide evidence that trade-throughs originate from informed traders with a priority of execution speed over price. Third, we analyze a new and comprehensive long-term set of data. Where most studies on competition and fragmentation are laid out as event studies with a comparably short after event period, our analysis covers 20 months, which makes an investigation of long-term effects possible. Additionally, to our best knowledge, we are the first to analyse explicitly stocks from Switzerland, which is not a member of the European Union and, therefore, to a lesser extent affected by MiFID.

The remainder of this paper is organized as follows. The next section reviews the literature and Section 3 outlines the data. Section 4 presents measures of liquidity and fragmentation, while Section 5 analyzes trade-throughs. Finally, Section 6 concludes.

\section{Literature Review}

There is a large body of literature, which analyzes the effects of liquidity fragmentation on market quality on a theoretical and empirical level. However, it is inconclusive about the question, whether fragmentation leads to an increase or decrease in market quality (see also Degryse (2009), Storkenmaier \& Wagener (2010) and Chlistalla \& Lutat (2011)).

Centralized trading reduces search and coordination costs for traders and 
could, therefore, be the optimal framework regarding market quality. Pagano (1989) and Chowdhry \& Nanda (1991) argue that liquidity tends to concentrate on one trading venue. Mendelson (1987) and Madhavan (1995) analyze theoretically the effects of liquidity fragmentation and show that fragmentation can decrease market quality. In Madhavan (1995) a model which explains liquidity fragmentation in the context of disclosure is proposed. In this model fragmentation can decrease market quality, but due to heterogenous preferences of market participants regarding disclosure of their trades, liquidity not necessarily concentrates. Amihud, Lauterbach \& Mendelson (2003) provide empirical evidence for benefits of consolidation by the analysis of corporate warrants from the Tel-Aviv Stock Exchange. However, they state that the cost of fragmentation is likely to be reduced under advanced trading systems.

Bennett \& Wei (2006) find improved market quality in terms of liquidity provision and price efficiency for stocks that switched from NASDAQ to the NYSE. This improvement is attributed to order flow concentration. It increases market quality in particular for less liquid stocks while the competition among trading platforms could still improve market quality for highly liquid stocks. With a sample of NYSE and Nasdaq stocks O'Hara \& Ye (2011) find no evidence for a decrease in market quality due to fragmentation. Moreover, fragmentation appears to be most beneficial for small stocks ${ }^{11}$. Christie

\footnotetext{
${ }^{11}$ Regarding the findings of Bennett \& Wei (2006), O'Hara \& Ye (2011) state that the findings of improved measures of market quality related to the move of the listing from Nasdaq to NYSE could be due to size effects of the stocks, rather than a consolidation of liquidity. According to O'Hara \& Ye (2011) the stocks that move from Nasdaq to NYSE tend to be the larger Nasdaq firms due to the listing standards of the two exchanges. For larger Nasdaq firms O'Hara \& Ye (2011) find no significant differences between fragmentation and consolidation.
} 
\& Schultz (1994) find evidence that NASDAQ market makers were able to earn rents by posting too wide spreads. When this was made public, spreads suddenly narrowed as shown in Christie, Harris \& Schultz (1994). These study show that the concentration of liquidity in one market place does not necessarily lead to competition among market makers and, therefore, does not fully enforce liquidity. In contrast, competition among trading venues may lead to better conditions, related services and lower prices for traders which could finally result in enhanced market quality. Boehmer \& Boehmer (2003) find evidence for improved market quality for ETFs that started to trade on the NYSE after having been traded on other platforms, which they attribute to enhanced competition for order flow.

Several studies analyze the competition between NASDAQ and ECNs. Barclay, Hendershott \& McCormick (2003), e.g., conclude that ECN trading explains more of the stock-price variance than trading on NASDAQ and thus ECNs are able to attract more informed traders. Fink, Fink \& Weston (2006) also find evidence for positive effects of enhanced competition between NASDAQ and ECNs and state that cost-competition for trading outweighs potentially negative effects driven by fragmentation.

The theoretical underpinning for effects of fragmentation on market quality follows two main strands. On the one hand positive network externalities through consolidation are emphasized, which means that fragmentation of liquidity should have negative effects on market quality. On the other hand competition among trading venues is seen as the main driver for enhanced market quality for the market participants. O'Hara \& Ye (2011) argue that smart order routing, the existence of a consolidated tape and a rule prohibit- 
ing trade-throughs ${ }^{12}$ lead to a virtual consolidation of U.S. equity markets although fragmentation has increased. This hypothesis combines the two strands of argumentation by explaining how increased competition through fragmentation leads to increased market quality without the negative effects due to the loss of consolidation.

MiFID however neither requires a consolidated tape, nor prohibits tradethroughs. The emergence of a virtual consolidated market for European equities is thus questionable. If the lack of a consolidated tape and a rule prohibiting trade-throughs prevents the emergence of a virtual consolidated market as discussed by O'Hara \& Ye (2011), trade-throughs would be evidence for market participants which do not monitor all trading venues and, therefore, trade at suboptimal prices. However, if trade-throughs express traders' priority of execution speed over price, the existence of trade-throughs would not provide evidence for a deterioration in market quality nor against the concept of a virtual consolidated market. Therefore, the analysis of trade-throughs is important for the understanding of the consequences of the different regulations in the U.S. and Europe on liquidity fragmentation and market quality.

There are comparably few empirical studies analyzing the effects of fragmentation of European equity trading related to the implementation of MiFID. Hengelbrock \& Theissen (2009) analyze the simultaneous market entry of Turquoise in 14 European countries, the determinants of its market share

\footnotetext{
${ }^{12} \mathrm{~A}$ trade-through is the execution of an order at a certain price, although a better price is offered on another exchange. Foucault \& Menkveld (2008) ascribe high trade-through rates to investors not using smart routers to route their trades to the market offering the best available price. See Section 5 for more details.
} 
and the effects on market quality in terms of liquidity and bid-ask spreads. Their main findings are that the market share of Turquoise is higher for firms with higher market capitalization, higher free float and lower volatility. A panel analysis provides evidence for a decrease in spreads and weak evidence for increased volume after the introduction of Turquoise. In another event study Chlistalla \& Lutat (2011) analyze the market entry of Chi-X in France. They provide evidence that market quality does not suffer from the entrance of a new competitor and the accompanying fragmentation of liquidity. Gresse (2010) analyzes measures of liquidity and market quality on regulated markets and MTFs for a sample of 140 LSE and Euronext listed stocks over four one month periods between October 2007 and September 2009 and finds no evidence for a decrease in market quality.

Foucault \& Menkveld (2008) study the entrance of the London Stock Exchange with its MTF EuroSETS in the Dutch stock market and the implications on the limit order market operated by Euronext. They find, that the consolidated order book after the entry of EuroSETS is deeper, i.e., overall liquidity is higher. Furthermore, they describe a negative relation between the rate of trade-throughs at the expense of EuroSETS and the liquidity supply on this market. With a high rate of trade-throughs for a particular stock, the probability of execution on EuroSETS is lower. Accordingly, the liquidity supply on EuroSETS would also be lower.

Riordan, Storkenmaier \& Wagener (2010) analyze competition and market quality in fragmented markets for the FTSE 100 constituents across the London Stock Exchange (LSE) and the three MTFs Chi-X, BATS Europe and Turquoise with a sample covering 29 trading days. They find evidence 
for an increase in market quality in terms of quoted spreads and a shift of price discovery from LSE towards Chi-X. Storkenmaier \& Wagener (2011) analyze market coordination, i.e., arbitrage opportunities (crossed market quotes) and subotpimal executions (trade-throughs) within the same sample period and conclude that the competition among trading venues lead to an alignment of prices. A similar conclusion is drawn by Spankowski, Wagener \& Burghof (2012), who analyze intraday patterns on the LSE and three MTFs and find evidence for a convergence across different trading venues. Degryse, de Jong \& van Kervel (2011) focus on the effects of dark trading on liquidity. They find a negative impact of dark trading on liquidity, while evidence is provided that fragmentation increases liquidity.

\section{Data}

We conduct our analysis for the constituents of the SMI Expanded index that includes the 50 largest Swiss stocks. Stocks that are not traded on the three MTFs Chi-X, BATS Europe and Turquoise and stocks where data is not available are excluded. Our final sample in Table 1 consists of 29 stocks.

[Insert Table 1 here]

We obtain intraday trade and quote data from Thomson Reuters Tick History for the Swiss exchange and the MTFs Chi-X, BATS Europe and Turquoise. Our sample covers a period of 433 trading days between November 3, 2008 and June 30, 2010 (20 months) and is, therefore, significantly larger than in comparable studies. The trade data contains the number of stocks traded and 
the price. The quotes data contains changes in the orderbook on the best bid and ask level ${ }^{13}$. Trade and quote data is timestamped to the millisecond. The data covers trades executed in the limit order book of the Swiss exchange or the three MTFs Chi-X, BATS Europe and Turquoise, but it does not include trades executed by systematic internalizers, dark pools or OTC venues.

For our analysis we build one-second snapshots of historical order books containing the best bid and ask price and the corresponding volumes. Historical trade data is aggregated to one-second intervals by summing up trading volume and calculating the volume weighted average price. Historical trade and quote data is calculated for every stock on every trading venue from 09:00:00 (CET) until 17:15:00 (CET) on each trading day ${ }^{14}$.

To analyze size effects, we group the stocks into three subsamples according to their average daily market capitalization during the sample period. Table 1 shows the attribution of the stocks to the subsamples. Stocks L contains the 10 largest stocks, Stocks M contains the 10 following stocks and Stocks $\mathrm{S}$ the remaining 9 stocks. The daily market capitalization per company during the sample period is retrieved from Thomson Reuters Datastream.

\footnotetext{
${ }^{13}$ Our data does not include iceberg orders and hidden liquidity.

${ }^{14}$ Continuous trading on the Swiss exchange takes place between 09:00:00 (CET) and 17:20:00 (CET) followed by the closing auction, see SIX Swiss Exchange (2010). We exclude the closing auction from our analysis and discard trade and quote data with a timestamp after 17:15:00 (CET).
} 


\section{Fragmentation and Market Quality}

Table 2 shows the fragmentation of liquidity. Panel A presents the market share in terms of average daily trading volume, Panel B in terms of average daily number of trades for the four trading venues.

[Insert Table 2 here]

The fragmentation index $(F I)$ is the reciprocal of a Herfindahl index ${ }^{15}$ based on the market share on different trading venues, i.e.,

$$
F I=\left(\sum_{k \in K} M S_{k}^{2}\right)^{-1}
$$

where $K=\{S I X, B S, C H I, T Q\}$ denotes the trading venue Swiss exchange (SIX), BATS Europe (BS), Chi-X (CHI) and Turquoise (TQ), respectively. $M S_{k}$ denotes the market share of trading venue $k$ for $k \in K$ in terms of the trading volume and the number of trades, respectively. $F I$ is, therefore, a measure for the concentration and takes a minimum of 1 if trading is fully concentrated on one market. An increase in the fragmentation index $F I$ is related to an increase in dispersion on different venues.

The Swiss exchange as the traditional and established market attracts the highest fraction in terms of trading volume (80.86\%) as well as the number of trades (72.34\%). The three MTFs exhibit a substantially and statistically highly significant lower market share in average daily trading volume with $11.49 \%$ for Chi-X, 5.01\% for Turquoise and 2.64\% for BATS Europe and

\footnotetext{
${ }^{15}$ The Fidessa Fragmentation Index is calculated analogously. See also Gresse (2010), who uses the same measure for fragmentation.
} 
in the average daily number of trades with $16.29 \%$ for Chi-X, $6.98 \%$ for Turquoise and $4.40 \%$ for BATS Europe. As the market share in terms of the number of trades is higher for all MTFs than the market share in terms of trading volume, it follows that the average trade size is lower on the MTFs than on the Swiss exchange. For the Swiss exchange the average trading volume per trade equals TCHF 25.5, whereas the average trading volume per trade on the MTFs is TCHF 13.4 for BATS Europe, TCHF 16.0 for Chi-X and TCHF 16.1 for Turquoise, i.e., on average $40 \%$ less on the MTFs than on the Swiss exchange.

The results for the subsamples show that fragmentation increases for the higher capitalized stocks. The fragmentation index is 1.55 for the trading volume and 1.97 for the number of trades for Stocks L. Stocks M exhibits a lower degree of fragmentation for trading volume $(F I=1.44)$ and for the number of trades $(F I=1.76)$ and the highest concentration in trading can be found for Stocks $\mathrm{S}$ with $F I=1.26$ for trading volume and $F I=1.43$ for the number of trades. Figure 1 shows the development of the fragmentation index $(F I)$ over the sample period together with the corresponding trading volume and the corresponding number of trades.

\section{[Insert Figure 1 here]}

Figure 1 shows a steady increase in fragmentation over the sample period. For trading volume the fragmentation is rather stable until June 2009 and increases between June 2009 and June 2010. A temporary decrease of FI in December 2009, which is more pronounced for the trading volume than for the number of trades, coincides with a decrease in the overall trading activity 
reflected in total trading volume and the total number of trades. Overall, the fragmentation is increasing for all subsamples, however, the increase is more pronounced for the higher capitalized stocks.

To assess market quality we calculate four liquidity measures that capture different dimensions of liquidity ${ }^{16}$ : tightness, time and depth of the order book. Two spread measures are used to describe tightness, the relative spread $\left(R S_{s}\right)$, calculated as

$$
R S_{s}=\frac{p_{s}^{A}-p_{s}^{B}}{p_{s}^{M}}
$$

and the relative effective spread $\left(R S_{s}^{e f f}\right)$ calculated as

$$
R S_{s}^{e f f}=\frac{\left|p_{s}-p_{s}^{M}\right|}{p_{s}^{M}}
$$

where $s$ denotes the one-second intraday interval and $p_{s}^{A}$ and $p_{s}^{B}$ denote the ask price and the bid price, respectively, related to interval $s . p_{s}^{M}$ denotes the mid price of interval $s$ and is calculated as

$$
p_{s}^{M}=\frac{p_{s}^{A}+p_{s}^{B}}{2}
$$

$p_{s}$ denotes the volume weighted average price in interval $s$. Therefore, the spread measure $R S_{s}$ is based on the quotes at the time of the trade and $R S_{s}^{e f f}$ on the realized execution price, which makes $R S_{s}^{e f f}$ the relevant measure from the point of view of a market participant ${ }^{17}$. Turnover $\left(V_{s}\right)$ takes the

\footnotetext{
${ }^{16}$ Liquidity is well established as a multi-dimensional concept. Therefore, most authors use multiple measures for capturing different dimensions of liquidity, e.g., Chordia, Roll \& Subrahmanyam (2000) and Chordia, Roll \& Subrahmanyam (2001).

${ }^{17}$ See also Hendershott \& Jones (2005) and O'Hara \& Ye (2011).
} 
time dimension of liquidity into account and is calculated as

$$
V_{s}=\sum_{j=1}^{N_{s}} p_{j} \cdot q_{j}
$$

where $p_{i}$ and $q_{i}$ denote the price and the number of stocks traded and $N_{s}$ the number of trades within the one-second interval $s$. The depth dimension of liquidity is captured by calculating the dollar depth $\left(D \$_{s}\right)$ as

$$
D \$_{s}=\frac{q_{s}^{A} \cdot p_{s}^{A}+q_{s}^{B} \cdot p_{s}^{B}}{2}
$$

where $q_{s}^{A}$ and $q_{s}^{B}$ denote the quoted number of stocks in interval $s$ on the ask side and bid side, respectively, i.e., the dollar depth measures the average quoted volume of the bid and ask side of the order book in every one-second interval. With these liquidity measures we gather the same information as Bessembinder \& Kaufman (1997), however, we are able to process the full sample at once and, therefore, do not rely on their multistage methodology. Average liquidity measures across trading venues and subsamples are in Table 3.

\section{[Insert Table 3 here]}

The Swiss exchange provides the highest liquidity according to all liquidity measures. The relative spread $R S$ for the pooled sample on Chi-X, BATS Europe and Turquoise is $0.33 \%-0.38 \%$ which equals approximately two times the relative spread on the Swiss exchange of $0.16 \%$. The relative effective spread $R S^{e f f}$ on the Swiss exchange for the pooled sample is $0.06 \%$ which equals approximately one third of the relative spread. The same proportion 
can be seen in $R S^{e f f}$ for Chi-X, BATS Europe and Turquoise with $R S^{\text {eff }}$ between $0.08 \%-0.09 \%$. The fact that the relative effective spread is smaller than the relative spread shows that trades are executed within the quote, i.e., not at the offered prices according to the order book ${ }^{18}$. The spread measures decrease with increasing market capitalization. Turnover $V$ and dollar depth $D \$$ show a similar pattern, as they are higher on the Swiss exchange than on the MTFs and increasing with market capitalization. The differences between the liquidity measures on the Swiss exchange and the MTFs are all highly significant.

According to the analyzed liquidity measures, Chi-X is the MTF with the highest market quality, followed by Turquoise and BATS Europe. Figure 2 shows how the liquidity measures evolve over the sample period. The upper panel shows the relative spread $R S$ and the relative effective spread $R S^{e f f}$, weighted with the corresponding turnover per trading venue. The lower panel shows turnover $V$ and dollar depth $D \$$, both in log-scales.

\section{[Insert Figure 2 here]}

According to Figure 2 the spread measures are decreasing over the sample period for all subsamples and the spreads for the higher capitalized stocks are consistently lower than for the smaller stocks. Turnover does not show a clear trend over the sample period while dollar depth, especially for Stocks L, is increasing over time which is consistent with Foucault \& Menkveld (2008), who also find a deeper consolidated order book after the entrance of the MTF EuroSETS in the Dutch stock market. Figure 2 clearly shows an increase in

\footnotetext{
${ }^{18}$ See Chordia et al. (2000) and Chordia et al. (2001) who also find substantially lower relative effective spreads compared to the relative spreads.
} 
market quality which coincides with a steady increase in fragmentation.

We follow Gresse (2010) and provide a multivariate regression analysis of the liquidity measures. Two multivariate fixed effects regression models of spread and depth measures are presented, where fragmentation enters as independent variable in the second regression model. We define the first regression model as

$$
L M_{i, t}^{k}=\alpha_{1}+\beta_{1} V_{i, t}+\beta_{2} \sigma_{i, t}+\beta_{3} \log M C A P_{i, t}+\beta_{4} D_{i}+\epsilon_{i, t},
$$

where $L M_{i, t}^{k}$ denotes the liquidity measures $R S, R S^{\text {eff }}$ and $\log D \$$ for stock $i$ and month $t$, respectively. The regressors are monthly averages of daily turnover, denoted by $V_{i, t}$, daily volatility $\sigma_{i, t}$ which is measured as standard deviation of the log returns and the logarithm of daily market capitalization $\log M C A P_{i, t}$.

We expect market quality to deteriorate in turbulent market phases, i.e., increasing spread measures and a decreasing depth for high volatility and, therefore, a positive sign for the coefficient of $\sigma$ for the spread measures and a negative sign for the depth measure. Market quality is expected to be higher for large stocks, which implies a negative sign of the coefficient of $\log M C A P$ and $V$ for the spread measures and a positive sign for the depth measure. We include company fixed effects, denoted by $D_{i}$, in the regression model and use Newey-West standard errors to account for heteroskedasticity and autocorrelation. We define the second regression model as

$$
L M_{i, t}^{k}=\alpha_{1}+\beta_{1} F I_{i, t}+\beta_{2} V_{i, t}+\beta_{3} \sigma_{i, t}+\beta_{4} \log M C A P_{i, t}+\beta_{5} D_{i}+\epsilon_{i, t}
$$


i.e., the fragmentation index $F I_{i, t}$ is also incorporated as independent variable. From Figure 2, we expect fragmentation to be an indication of enhanced competition, which improves market quality for investors. Therefore, we expect the coefficient of $F I$ to be negative for the spread measures and positive for the depth measure. The results for the two regression models are given in Table 4 for $R S$, in Table 5 for $R S^{e f f}$ and in Table 6 for $\log D \$$.

[Insert Tables 4-6 here]

The upper panel of Table 4 shows that the coefficient for $\log M C A P$ is negative and significant on the $1 \%$ level for the pooled sample which means that the relative spread is decreasing for higher capitalized stocks. This relation holds for the subsamples Stocks M and Stocks S. The coefficient for Stocks L is positive, although not significant. The sign of $\sigma$ is positive which indicates an increasing relative spread for increasing intraday volatility. It is highly significant for the pooled sample and all subsamples. The coefficient of turnover is negative for the pooled sample and the subsamples and highly significant for the three subsamples, which indicates decreasing relative spreads for increasing trading activity. The adjusted $R^{2}$ for the pooled sample with the first regression model is $82 \%$.

The second regression model in the lower panel of Table 4 includes fragmentation as independent variable. The coefficient of $\log M C A P$ remains negative and highly significant for the pooled sample. The signs of the coefficients for the subsamples do not change, however the result for subsample Stocks M loses significance. The results for $\sigma$ and $V$ are similar to the first regression model. The coefficient of $F I$ is negative and significant for the 
pooled sample and the subsamples Stocks M and Stocks S which indicates decreasing spreads for increasing fragmentation. This is evidence for a positive effect of fragmentation on market quality. The adjusted $R^{2}$ s for all subsamples are higher for the second regression model which includes fragmentation as independent variable.

Table 5 presents the results for the relative effective spread. They are similar to the results for the relative spread. The coefficient for $\log M C A P$ in both regression models is significantly negative for the pooled sample. The positive sign for Stocks L is not significant. $\sigma$ has a positive and highly significant coefficient in both regression models for the pooled sample and all subsamples and the coefficients for $V$ are significantly negative for the subsamples and insignificant for the pooled sample. The lower panel of Table 5 presents results for the second regression model where fragmentation is included as independent variable. The coefficient of $F I$ is negative for the pooled sample and all the subsamples and significant for the subsamples Stocks $\mathrm{M}$ and Stocks $\mathrm{S}$. The adjusted $R^{2} \mathrm{~S}$ for the second regression model are higher than for the first regression model for the pooled sample and all subsamples.

Table 6 presents regression results for dollar depth. The coefficient of $\log M C A P$ is significantly positive for the pooled sample, Stocks L and Stocks $\mathrm{M}$ in the first regression model and for the pooled sample and all the subsamples in the second regression model. This indicates that depth increases with market capitalization. $\sigma$ has a significantly negative coefficient for the pooled sample, Stocks M (first regression model) and Stocks S (both regression models). The sign of the coefficient for Stocks L is positive but 
not significant. The coefficient of $V$ is significantly positive for the pooled sample which indicates that higher trading activity is positively related to a deeper orderbook. Results for the subsamples are not clear as the coefficient is positive for Stocks L and Stocks S but negative for Stocks M, although not significant. The lower panel of Table 6 presents again regression results which include $F I$ as regressor. The coefficient of $F I$ is positive and highly significant on the $1 \%$ level for the pooled sample and all the subsamples which indicates that the dollar depth increases with increasing fragmentation for all subsamples. Adjusted $R^{2}$ s are also higher for the second regression model than for the first one.

So far the regression analysis of the liquidity measures provides strong evidence for increasing market quality in terms of lower spreads and deeper orderbooks related to the fragmentation of trading volume. Furthermore, the inclusion of the fragmentation index yields higher $R^{2}$ s for all three liquidity measures and all subsamples.

\section{Analysis of Trade-Throughs}

A trade-through is defined as an order, executed at a price, that is worse than the best quoted price, i.e., the stock could have been bought (sold) on another trading venue at a lower (higher) price. In the United States tradethroughs are prohibited for certain financial instruments and trading venues, i.e., best execution is understood as a best price policy. MiFID on the other hand does not regard price as the only dimension of best execution. Other dimensions include execution speed or the probability of execution. Foucault 
\& Menkveld (2008) discuss explanations for trade-throughs like a trade-off between finding the best execution price and monitoring costs for different trading venues or the trade-off between execution price and execution speed.

We compare for every one-second interval $s$ the price with the best bid and ask price (BBO) over all trading venues. BBO corresponds to an artificial consolidated tape for the respective stocks. In calculating the BBO prices we follow Hasbrouck (2010) by letting a price on a certain trading venue be valid until it is replaced and by keeping the order of quote changes according to the timestamp (in milliseconds). As we use previous-tick interpolation to allocate trades within the one-second interval, we compare the price of interval $s$ to the best bid and ask prices of interval $s-1$ and $s$, which ensures that we really capture the trade-throughs. A trade is flagged as trade-through, if either

$$
p_{s}>\max \left(p_{s-1}^{A}, p_{s}^{A}\right)
$$

or

$$
p_{s}<\min \left(p_{s-1}^{B}, p_{s}^{B}\right)
$$

where $p_{s}$ denotes the volume weighted average price of interval $s, p_{s-1}^{B}$ and $p_{s-1}^{A}$ denote the best bid and best ask prices among all trading venues of interval $s-1$ and $p_{s}^{B}$ and $p_{s}^{A}$ of interval $s$, respectively. Table 7 shows the fraction of trade-throughs in terms of trading volume and the number of trades for the four trading venues.

\section{[Insert Table 7 here]}

The average fraction of trade-throughs in terms of trading volume is $10.35 \%$ 
for the pooled sample on the Swiss exchange and $5.11 \%-6.66 \%$ for the MTFs. Subsample Stocks S exhibits in general a lower fraction of tradethroughs than the subsamples with larger capitalized stocks. The lower fragmentation of these stocks makes trade-throughs less probable. The fraction of trade-throughs in terms of the number of trades shows similar results with a fraction of trade-throughs of $10.00 \%$ for the pooled sample on the Swiss exchange and fractions of $4.79 \%-6.86 \%$ on the MTFs and with shares of trade-throughs that are higher for the subsamples with higher capitalized stocks. Our estimated ranges for trade-throughs are similar to Storkenmaier \& Wagener (2011), but significantly lower than in Foucault \& Menkveld (2008). Storkenmaier \& Wagener (2011) ascribe this fact to smart order routing which is of higher relevance today, than in the period analyzed by Foucault \& Menkveld (2008) (May 2004).

We follow the approach of Storkenmaier \& Wagener (2011) and analyze determinants of trade-throughs by means of bivariate logistic regression models. Measures from the consolidation of all trading venues enter as independent variables in the first model. Formally, the model is defined as

$$
\begin{aligned}
& I_{i, s}=\beta_{1} R S_{i, s}^{B B O}+\beta_{2} \log D \$_{i, s}^{c u m}+\beta_{3} \# \text { Shares }_{i, s}+\beta_{4} \log V_{i, s}^{15}+ \\
& \beta_{5}\left(\sigma_{i, s}^{\text {real }}\right)^{2}+\beta_{6} D i r_{i, s}+\beta_{7} M I_{i, s}+\beta_{8} D_{i}+\beta_{9} D_{s}+\epsilon_{i, s},
\end{aligned}
$$

where $I_{i, s}$ denotes the logarithm of the odds ratio of a trade-through. The relative spread of trade $s$ in stock $i$ measured with the best prevailing bid and offer prices among all trading venues is denoted by $R S_{i, s}^{B B O}$. The logarithm of the cumulative dollar depth over all trading venues is denoted by $\log D \$_{i, s}^{\text {cum }}$ 
and the number of shares traded by \#Shares $i_{i, s} . \log V_{i, s}^{15}$ is the $\operatorname{logarithm}$ of the cumulative trading volume over all trading venues within 15 minutes before a trade occurs and $\left(\sigma_{i, s}^{\text {real }}\right)^{2}$ equals the squared 15 minute log-return of the mid price over all trading venues. The trade direction $D i r_{i, s}$ is set to 1 for a buyer initiated trade and -1 for a seller initiated trade and we determine trade direction by the algorithm proposed by Lee \& Ready (1991). The market impact of trade $s$ in stock $i$, denoted by $M I_{i, s}$, is calculated as

$$
M I_{i, s}=\frac{\left|p_{i, s+5}^{M}-p_{i, s}^{M}\right|}{p_{i, s}^{M}},
$$

i.e., as the absolute value of the percentage change of the mid price 5 minutes after the trade. $M I$ is used to measure the price impact of a trade, see for instance Bessembinder \& Kaufman (1997), Hasbrouck (2007) or Storkenmaier \& Wagener (2011). Company specific fixed effects $\left(D_{i}\right)$ and day specific fixed effects $\left(D_{s}\right)$ are included in the regression model. We define the second regression model as

$$
\begin{aligned}
I_{i, s}= & \beta_{1} R S_{i, s}^{\text {Market }}+\beta_{2} \log D \$_{i, s}^{\text {Market }}+\beta_{3} \# \text { Shares }_{i, s}+\beta_{4} \log V_{i, s}^{15}+ \\
& \beta_{5}\left(\sigma_{i, s}^{\text {real }}\right)^{2}+\beta_{6} \operatorname{Dir}_{i, s}+\beta_{7} M I_{i, s}+\beta_{8} D_{i}+\beta_{9} D_{s}+\epsilon_{i, s},
\end{aligned}
$$

i.e., the measures from the consolidation of all trading venues are replaced by the respective measures of the venue where the trade is executed, i.e., $R S_{i, s}^{B B O}$ is replaced by the relative spread of the respective market, denoted by $R S_{i, s}^{\text {Market }}$ and $\log D \$_{i, s}^{c u m}$ is replaced by the dollar depth of the respective market, denoted by $\log D \$_{i, s}^{\text {Market }}$. 


\section{[Insert Table 8 here]}

Panel A of Table 8 presents the results for the first regression model without market impact as independent variable. The coefficient of the relative spread is significantly negative for the pooled sample and for two subsamples because the probability of a trade-through increases when the spread between the best bid and ask price among all trading venues decreases. Cumulative dollar depth has a highly significant negative coefficient for the pooled sample and all subsamples.

The coefficients of \#Shares, $V^{15}$, $\sigma^{\text {real }}$ and Dir are all positive and highly significant for the pooled sample. This means that the probability of a tradethrough is generally higher for larger trades (higher \#Shares), for trades during more active market phases (higher $V^{15}$ and $\sigma^{r e a l}$ ) and for buyer initiated trades (Dir). Significance is confirmed by most of the subsamples. The inclusion of market impact as independent variable leads to the results in Panel B of Table 8. The coefficients of all independent variables and their significance are similar to the results in Panel A for all subsamples. The coefficient of $M I$ is positive and highly significant for the pooled sample and for all subsamples, indicating that the probability of a trade-through is higher for trades which exhibit a higher market impact. Therefore, trade-throughs are mainly caused by informed traders, where execution speed has a higher priority than getting the best price over all trading venues. The robustness of this result is confirmed by the subsamples.

Panel $\mathrm{C}$ of Table 8 presents results for the second regression model, where we replace the consolidated liquidity measures by market specific liquidity measures. The relative spread of the respective market where the trade- 
through occurs is negatively related to the probability of a trade-through. Intuitively, the probability of another trading venue offering a better price increases when the relative spread of a specific market increases. The coefficient of dollar depth on the respective market is also negative and significant, which means that cumulative dollar depth for the whole market and dollar depth on individual markets are negatively related to the probability of a trade-through. The coefficients of \#Shares, $V^{15}, \sigma^{\text {real }}$ and Dir are again all positive and highly significant for the pooled sample and robust for the subsamples. The inclusion of the independent variable $M I$, in Panel $\mathrm{D}$ of Table 8, leads to similar results for the coefficients and the significance levels. The coefficient of $M I$ is positive and highly significant on the $1 \%$ level for the pooled sample and all subsamples, indicating again a higher probability of a trade-through for trades with higher market impact. The robustness of this relation is again confirmed by the subsamples.

The results of the two regression models provide strong evidence for the hypothesis that trade-throughs are caused by informed market participants for whom execution speed is more relevant than execution price. Therefore, the lack of a rule prohibiting trade-throughs does not necessarily deteriorate market quality. Table 9 presents liquidity measures for trades that are executed at a price within the best prevailing bid and ask price among all trading venues (BBO) and for trade-throughs (tt). Panel A shows the results for all trades, i.e., for the consolidation of trades that were executed on the Swiss exchange or on a MTF. Panel B and Panel C show only results for trades executed on the Swiss exchange and on the MTFs, respectively. We calculate the mean and the median of the relative effective spread $R S^{\text {eff }}$ and 
the market impact $M I$ for ordinary trades and trade-throughs and compare the mean of the two groups of trades with a standard t-test and the medians with a non-parametric Wilcoxon Rank Sum test.

[Insert Table 9 here]

Trade-throughs should exhibit a higher relative effective spread as the execution price of a trade-through lies per definition outside the best prevailing bid and ask prices among all trading venues, whereas the execution price of an ordinary trade lies within. Indeed, Panel A shows that the overall mean relative effective spread is 3 bps higher for trade-throughs than for ordinary trades for the pooled sample and the overall median relative effective spread is 2 bps higher for trade-throughs than for ordinary trades for the pooled sample. These differences are significant on the $1 \%$ significance level which confirms that our algorithm identifies trade-throughs.

The results are robust for the subsamples, where the difference is lower for the subsample with higher capitalized stocks. The overall mean market impact is 5 bps higher for trade-throughs than for ordinary trades for the pooled sample and the overall median market impact is 3 bps higher for tradethroughs than for ordinary trades for the pooled sample. These differences are highly significant on the $1 \%$ significance level and are confirmed by all three subsamples, where again the differences are larger for subsample Stocks S, i.e., for the stocks with lower market capitalization. This evidence supports the hypothesis that trade-throughs do not express a lack of market quality, but instead are caused by a time over price priority of informed traders.

As Barclay et al. (2003) show, ECNs attract more informed traders. 
Therefore, we analyze the relative effective spread and the market impact for trade-throughs and ordinary trades for the Swiss exchange and the MTFs separately. If MTFs tend to attract more informed traders and if tradethroughs express a time over price priority of informed traders, we would expect the difference in market impact for trade-throughs against ordinary trades to be higher on MTFs. Indeed, as Panel B and Panel C of Table 9 reveal, the mean market impact for trades on the Swiss exchange is 3 bps higher for trade-throughs than for ordinary trades, but 6 bps higher for trades executed on a MTF. The differences are highly significant. The same holds true for the median market impact which is about $1 \mathrm{bp}$ higher for tradethroughs than for ordinary trades on the Swiss exchange and around 4 bps for trades on MTFs, where all differences are highly significant.

The analysis of the subsamples shows that these differences are stable for different levels of market capitalization. The mean market impact of a trade-through against an ordinary trade is around 4 bps higher if the trade was executed on a MTF against the Swiss exchange for all three subsamples. The same holds true for the differences in the median market impacts for Stocks M and Stocks S, which are around 4bps higher for trades executed on MTFs against trades executed on the Swiss exchange and about 2 bps higher for Stocks L. Overall, the analysis of trades executed on the Swiss exchange and on the MTFs provides evidence for the hypothesis that trade-throughs originate in the time over price priority of informed traders and are, therefore, not necessarily a negative by-product of the fragmentation of liquidity. 


\section{Conclusion}

The implementation of MiFID served as a catalyst for the emergence of MTFs in Europe which lead to an increased fragmentation of liquidity in European equity trading. In contrast to the regulation in the United States MiFID does not include a rule for the prohibition of trade-throughs. It is not clear, if this prevents a virtual consolidation of the markets in Europe, as it is discussed for instance in O'Hara \& Ye (2011) for the United States.

We investigate a sample of 29 stocks from companies that are listed on the Swiss exchange and the three MTFs Chi-X, BATS Europe and Turquoise. Several liquidity measures, such as spread and depth measures, are calculated for a long-term sample that covers 20 months. By means of multivariate regression models we determine the long-run effect of fragmentation on market quality and find no evidence for a deterioration of market quality in the aftermath of the implementation of MiFID. In contrast, we find significantly positive effects of the fragmentation on spread and depth measures, which are confirmed by the analysis of different subsamples.

Additionally, we examine determinants of trade-throughs by bivariate logistic regression models and find evidence that trade-throughs are caused by informed traders who consider execution speed as more important than the best available price. The analysis of the market impact, which is larger after a trade-through than after an ordinary trade confirms this result. This difference is even more pronounced for trades that are executed on an MTF. Since previous studies found MTFs to attract more informed traders, this confirms that informed traders cause the trade-throughs. Our study provides 
evidence, that the fragmentation of trading in European equities markets did not deteriorate market quality, although a rule prohibiting trade-throughs is not included in MiFID. 


\section{References}

Amihud, Y., Lauterbach, B., \& Mendelson, H. (2003). The Value of Trading Consolidation: Evidence from the Exercise of Warrants. Journal of Financial and Quantitative Analysis, 38(4), 829-846.

Barclay, M. J., Hendershott, T., \& McCormick, D. T. (2003). Competition among Trading Venues: Information and Trading on Electronic Communications Networks. The Journal of Finance, LVIII(6), 2637-2665.

Bennett, P. \& Wei, L. (2006). Market structure, fragmentation, and market quality. Journal of Financial Markets, 9, 49-78.

Bessembinder, H. \& Kaufman, H. M. (1997). A Comparison of Trade Execution Costs for NYSE and NASDAQ-Listed Stocks. Journal of Financial and Quantitative Analysis, 32(3), 287-310.

Boehmer, B. \& Boehmer, E. (2003). Trading your neighbors ETFs: Competition or fragmentation? Journal of Banking $\& 3$ Finance, 27(9), 1667-1703.

Chlistalla, M. \& Lutat, M. (2011). Competition in securities markets: the impact on liquidity. Financial Markets and Portfoliol Management, 25(2), 149-172.

Chordia, T., Roll, R., \& Subrahmanyam, A. (2000). Commonality in liquidity. Journal of Financial Economics, 56(1), 3 - 28.

Chordia, T., Roll, R., \& Subrahmanyam, A. (2001). Market Liquidity and Trading Activity. The Journal of Finance, LVI(2), $501-530$.

Chowdhry, B. \& Nanda, V. (1991). Multimarket Trading and Market Liquidity. The Review of Financial Studies, 4(3).

Christie, W. G., Harris, J. H., \& Schultz, P. H. (1994). Why did NASDAQ Market Makers Stop Avoiding Odd-Eighth Quotes? The Journal of Finance, 49(5), 1841-1860.

Christie, W. G. \& Schultz, P. H. (1994). Why do NASDAQ Market Makers Avoid Odd-Eighth Quotes? The Journal of Finance, 49(5), 1813-1840.

Degryse, H. (2009). Competition between financial markets in Europe: what can be expected from MiFID? Financial Markets and Portfolio Management, 23, 93-103. 
Degryse, H., de Jong, F., \& van Kervel, V. (2011). The impact of dark trading and visible fragmentation on market quality. Working Paper.

EC (2004). Council Directive 2004/39/EC of 21 April 2004 on markets in financial instruments.

ECC (1993). Council Directive 93/22/EEC of 10 May 1993 on investment services in the securities field.

Fink, J., Fink, K. E., \& Weston, J. P. (2006). Competition on the Nasdaq and the growth of electronic communication networks. Journal of Banking E Finance, $30(9), 2537-2559$.

Foucault, T. \& Menkveld, A. J. (2008). Competition for Order Flow and Smart Order Routing Systems. The Journal of Finance, LXIII(1), 119 158.

Gresse, C. (2010). Multi-Market Trading and Market Liquidity. Working Paper.

Hasbrouck, J. (2007). Empirical Market Microstructure. New York: Oxford University Press.

Hasbrouck, J. (2010). The best bid and offer: A short note on programs and practices. Working Paper.

Hendershott, T. \& Jones, C. M. (2005). Trade-through prohibitions and market quality. Journal of Financial Markets, 8, 1-23.

Hengelbrock, J. \& Theissen, E. (2009). Fourteen at One Blow : The Market Entry of Turquoise. Working Paper.

Lee, C. M. C. \& Ready, M. J. (1991). Inferring Trade Direction from Intraday Data. Journal of Finance, 46(2), 733-746.

Madhavan, A. (1995). Consolidation, Fragmentation, and the Disclosure of Trading Information. Review of Financial Studies, 8(3), 579-603.

Mendelson, H. (1987). Consolidation, fragmentation, and market performance. Journal of Financial and Quantitative Analysis, 22, 187-207.

O'Hara, M. \& Ye, M. (2011). Is Market Fragmentation Harming Market Quality? Journal of Financial Economics, $100(3)$, 459-474.

Pagano, M. (1989). Trading Volume and Asset Liquidity. The Quarterly Journal of Economics, 104 (2), 255-274. 
Riordan, R., Storkenmaier, A., \& Wagener, M. (2010). Fragmentation, Competition and Market Quality : A Post-MiFID Analysis. Working Paper.

SIX Swiss Exchange (2010). Directive 3: Trading.

Spankowski, U. F., Wagener, M., \& Burghof, H.-P. (2012). Intraday Trading Patterns in Fragmented Markets - A Post MiFID Analysis. Working Paper.

Storkenmaier, A. \& Wagener, M. (2010). Research on Competition and Regulation in European Equities Trading: An Executive Summary. Working Paper.

Storkenmaier, A. \& Wagener, M. (2011). Do we need a European "National Market System"? Competition, arbitrage, and suboptimal executions. Working Paper. 


\section{Table 1 - Final Sample}

The table shows the final sample of 29 companies. It consists of the constituents of the SMI Expanded index that are listed on the MTFs Chi-X, BATS Europe and Turquoise. The SMI Expanded covers the SMI and SMIM indices and contains the 50 largest capitalized stocks of the Swiss market. We use the index constituents as on June 15, 2010. Additionally, we show the attribution of the stocks to the subsamples. It is based on the average daily market capitalization (MCAP) over the sample period November 3, 2008 until June 30, 2010. Market capitalization is retrieved from Thomson Reuters Datastream and is reported in billion Swiss francs. Subsample Stocks L contains the ten largest stocks of the final sample, Stocks $\mathrm{S}$ contains the nine smallest stocks and Stocks M the ten remaining stocks.

\begin{tabular}{llrc}
\hline Company & Symbol & MCAP & Subsample \\
\hline Nestle & NESN & 168.1 & \\
Novartis & NOVN & 135.2 & Stocks L \\
Roche & ROG & 113.8 & Avg. MCAP: 66.0 \\
Credit Suisse & CSGN & 53.2 & \\
UBS & UBSN & 51.3 & \\
ABB & ABBN & 43.0 & \\
Zurich Financial Services & ZURN & 32.4 & \\
Syngenta & SYNN & 24.1 & \\
Holcim & HOLN & 19.9 & \\
Swisscom & SCMN & 18.8 & \\
\hline Swiss Re & RUKN & 15.2 & \\
Synthes & SYST & 15.1 & Stocks M \\
Richemont & CFR & 14.9 & Avg. MCAP: 10.2 \\
Kuehne + Nagel & KNIN & 10.6 & \\
SGS & SGSN & 10.2 & \\
Adecco & ADEN & 9.2 & \\
Swatch Group I & UHR & 6.9 & \\
Actelion & ATLN & 6.9 & \\
Givaudan & GIVN & 6.6 & \\
Geberit & GEBN & 6.3 & \\
\hline Swatch Group N & UHRN & 5.3 & \\
Lonza & LONN & 4.9 & Stocks S \\
Baloise & BALN & 4.2 & Avg. MCAP: 3.2 \\
Swiss Life Holding & SLHN & 3.5 & \\
Nobel Biocare & NOBN & 3.2 & \\
Logitech & LOGN & 3.1 & \\
Clariant & CLN & 2.1 & \\
Petroplus & PPHN & 1.6 & \\
OC Oerlikon & OERL & 0.8 & \\
\hline
\end{tabular}




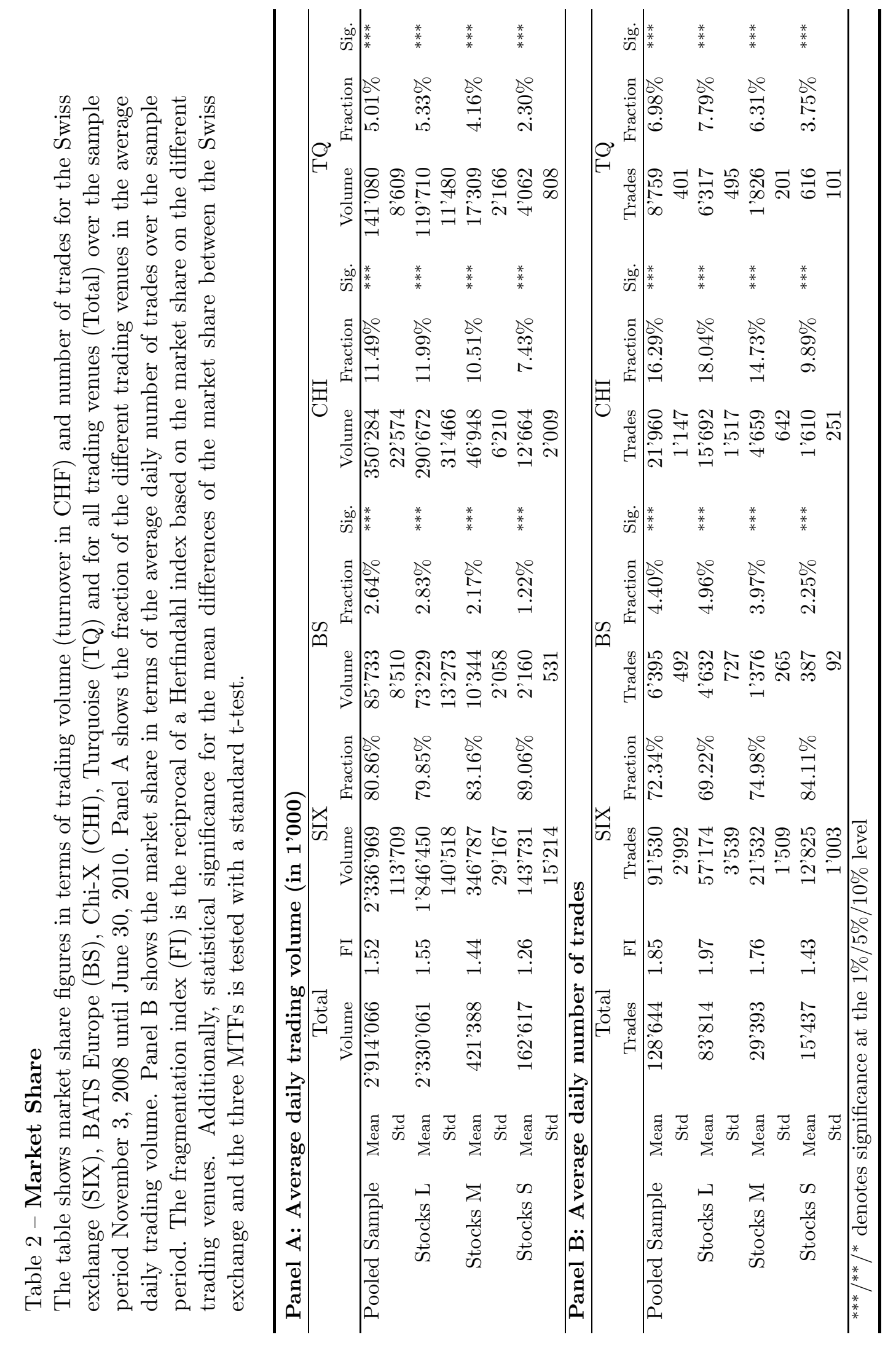


Table 3 - Liquidity Measures

The table shows liquidity measures for the Swiss exchange (SIX), BATS Europe (BS), Chi-X (CHI), Turquoise (TQ) across different subsamples. Two spread measures are presented, $R S$ denotes the relative spread and $R S^{\text {eff }}$ denotes the relative effective spread, calculated with the prevailing mid-price. $V$ denotes the average turnover per hour in CHF and $D \$$ is the dollar depth, measured as average posted volume on the bid and ask side of the order book. Additionally, statistical significance for the mean differences between the Swiss exchange and the three MTFs is tested with a standard t-test.

\begin{tabular}{|c|c|c|c|c|c|c|c|c|}
\hline \multicolumn{9}{|c|}{$R S$} \\
\hline & & SIX & BS & Sig. & $\mathrm{CHI}$ & Sig. & $\mathrm{TQ}$ & Sig. \\
\hline \multirow[t]{2}{*}{ Pooled Sample } & Mean & $0.16 \%$ & $0.34 \%$ & $* * *$ & $0.38 \%$ & $* * *$ & $0.33 \%$ & $* * *$ \\
\hline & Std & $0.09 \%$ & $0.46 \%$ & & $1.07 \%$ & & $1.08 \%$ & \\
\hline \multirow[t]{2}{*}{ Stocks L } & Mean & $0.10 \%$ & $0.29 \%$ & $* * *$ & $0.18 \%$ & *** & $0.19 \%$ & $* * *$ \\
\hline & Std & $0.04 \%$ & $0.47 \%$ & & $0.21 \%$ & & $0.41 \%$ & \\
\hline \multirow[t]{2}{*}{ Stocks M } & Mean & $0.15 \%$ & $0.35 \%$ & $* * *$ & $0.29 \%$ & *** & $0.33 \%$ & $* * *$ \\
\hline & Std & $0.05 \%$ & $0.39 \%$ & & $0.86 \%$ & & $1.34 \%$ & \\
\hline \multirow[t]{4}{*}{ Stocks S } & Mean & $0.23 \%$ & $0.39 \%$ & *** & $0.83 \%$ & *** & $0.56 \%$ & $* * *$ \\
\hline & Std & $0.12 \%$ & $0.52 \%$ & & $1.81 \%$ & & $1.34 \%$ & \\
\hline & & & $R S^{e f f}$ & & & & & \\
\hline & & SIX & BS & Sig. & $\mathrm{CHI}$ & Sig. & $\mathrm{TQ}$ & Sig. \\
\hline \multirow[t]{2}{*}{ Pooled Sample } & Mean & $0.06 \%$ & $0.09 \%$ & $* * *$ & $0.08 \%$ & $* * *$ & $0.08 \%$ & $* * *$ \\
\hline & Std & $0.04 \%$ & $0.15 \%$ & & $0.12 \%$ & & $0.11 \%$ & \\
\hline \multirow[t]{2}{*}{ Stocks L } & Mean & $0.04 \%$ & $0.07 \%$ & $* * *$ & $0.05 \%$ & $* * *$ & $0.05 \%$ & $* * *$ \\
\hline & Std & $0.01 \%$ & $0.14 \%$ & & $0.06 \%$ & & $0.09 \%$ & \\
\hline \multirow[t]{2}{*}{ Stocks M } & Mean & $0.05 \%$ & $0.10 \%$ & $* * *$ & $0.08 \%$ & *** & $0.08 \%$ & $* * *$ \\
\hline & Std & $0.02 \%$ & $0.16 \%$ & & $0.09 \%$ & & $0.09 \%$ & \\
\hline \multirow[t]{2}{*}{ Stocks S } & Mean & $0.08 \%$ & $0.12 \%$ & *** & $0.14 \%$ & *** & $0.13 \%$ & $* * *$ \\
\hline & Std & $0.05 \%$ & $0.14 \%$ & & $0.19 \%$ & & $0.15 \%$ & \\
\hline \multicolumn{9}{|c|}{$\bar{V}$} \\
\hline & & SIX & BS & Sig. & $\mathrm{CHI}$ & Sig. & $\mathrm{TQ}$ & Sig. \\
\hline \multirow[t]{2}{*}{ Pooled Sample } & Mean & $9^{\prime} 767^{\prime} 894$ & $358^{\prime} 340$ & $* * *$ & 1'464'092 & $* * *$ & $589 ' 678$ & $* * *$ \\
\hline & Std & $13^{\prime} 782^{\prime} 305$ & 1'031'524 & & 2'736'155 & & $1^{\prime} 043^{\prime} 423$ & \\
\hline \multirow[t]{2}{*}{ Stocks L } & Mean & $22^{\prime} 381^{\prime} 217$ & $887^{\prime} 624$ & $* * *$ & 3'523'297 & *** & $1^{\prime} 451^{\prime} 030$ & $* * *$ \\
\hline & Std & $17^{\prime} 030^{\prime} 503$ & $1^{\prime} 608^{\prime} 674$ & & 3'813'634 & & $1^{\prime} 391^{\prime} 390$ & \\
\hline \multirow[t]{2}{*}{ Stocks M } & Mean & 4'203'483 & $125^{\prime} 381$ & *** & $569^{\prime} 065$ & *** & $209 ' 806$ & *** \\
\hline & Std & 3'534'994 & $2499^{\prime} 377$ & & $752^{\prime} 690$ & & $262 ' 516$ & \\
\hline \multirow[t]{2}{*}{ Stocks S } & Mean & 1'935'770 & 29’091 & *** & $170^{\prime} 560$ & *** & $54^{\prime} 701$ & *** \\
\hline & Std & 1'843'876 & $64^{\prime} 301$ & & $243^{\prime} 436$ & & $97^{\prime} 949$ & \\
\hline
\end{tabular}


Table 3 - continued from previous page

\begin{tabular}{|c|c|c|c|c|c|c|c|c|}
\hline \multicolumn{9}{|c|}{$D \$$} \\
\hline & & SIX & BS & Sig. & $\mathrm{CHI}$ & Sig. & TQ & Sig. \\
\hline \multirow[t]{2}{*}{ Pooled Sample } & Mean & $182^{\prime} 093$ & $28^{\prime} 128$ & $* * *$ & $52^{\prime} 316$ & $* * *$ & $32 ' 204$ & *** \\
\hline & Std & 393 '843 & 78'010 & & $121 ' 840$ & & $52^{\prime} 583$ & \\
\hline \multirow[t]{2}{*}{ Stocks L } & Mean & $389^{\prime} 160$ & $54^{\prime} 674$ & $* * *$ & $111^{\prime} 850$ & $* * *$ & $66^{\prime} 574$ & $* * *$ \\
\hline & Std & $616 ' 209$ & $110^{\prime} 127$ & & $191^{\prime} 748$ & & $76^{\prime} 366$ & \\
\hline \multirow[t]{2}{*}{ Stocks M } & Mean & $92^{\prime} 245$ & 11'341 & $* * *$ & $27^{\prime} 021$ & $* * *$ & $18^{\prime} 443$ & *** \\
\hline & Std & $53 ' 250$ & $15^{\prime} 476$ & & $23^{\prime} 172$ & & $15^{\prime} 719$ & \\
\hline \multirow[t]{2}{*}{ Stocks S } & Mean & $51^{\prime} 849$ & $17^{\prime} 286$ & $* * *$ & $14^{\prime} 273$ & $* * *$ & 9'305 & $* * *$ \\
\hline & Std & $34^{\prime} 308$ & $68^{\prime} 220$ & & $16^{\prime} 986$ & & $10^{\prime} 374$ & \\
\hline
\end{tabular}



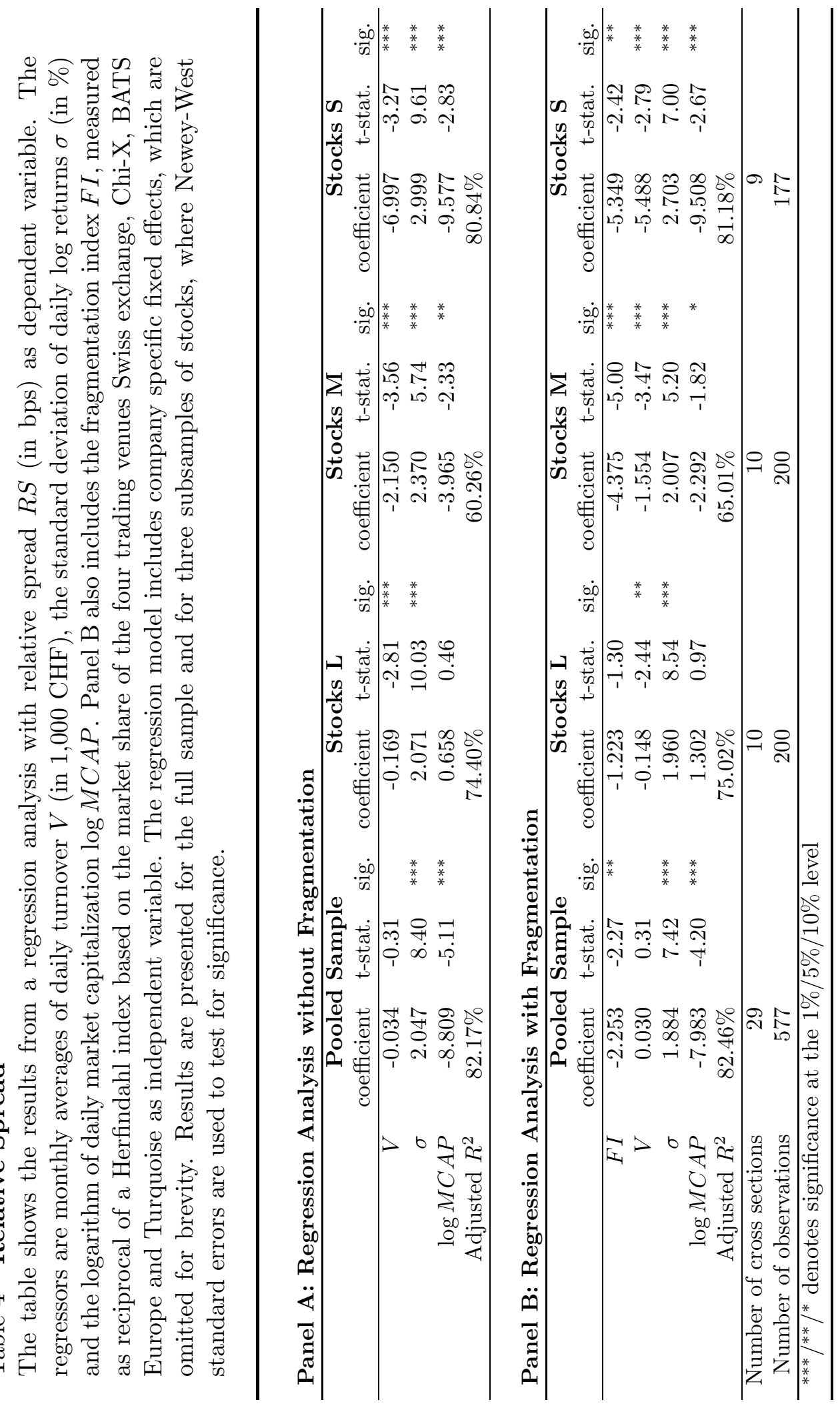


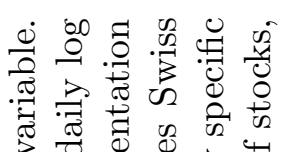
त

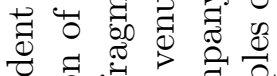
वृ 荢.

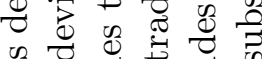
च च की $\Xi$ 需 $\leftarrow$ 范 ¿

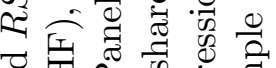
ซ

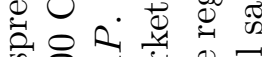
क \& 元 .

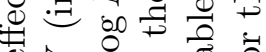
证氶

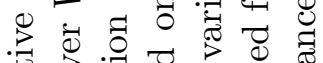

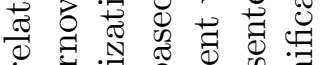

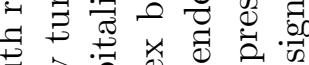

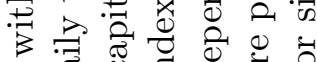
.

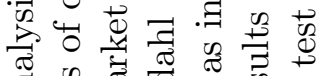
హี

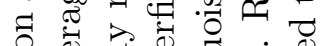

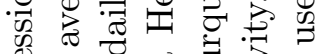

ซ 员

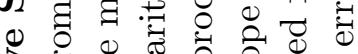
$\geq \notin+80.200$

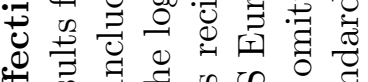

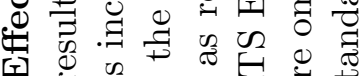
0

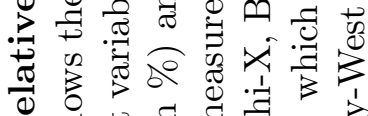

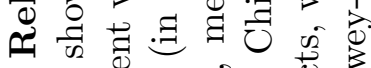
1 过

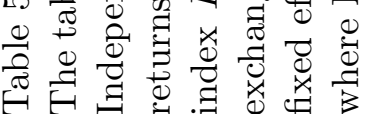
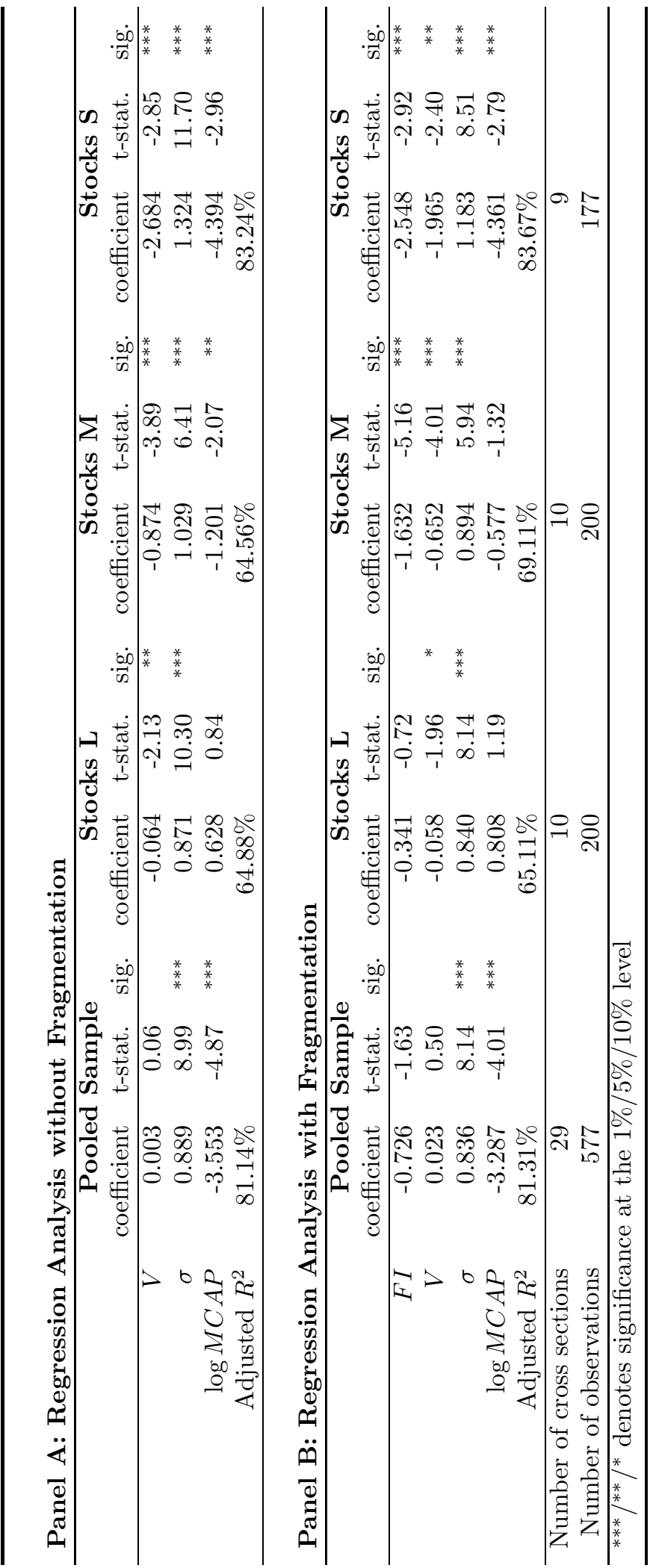


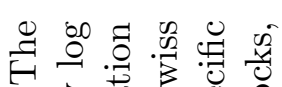

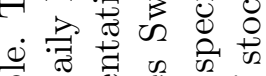

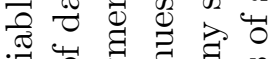
胥 尾. 包 व d 0

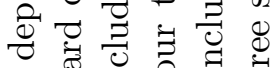
㐘 ๑

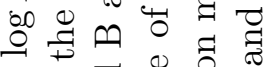
咅 ช 完 0 人 잉

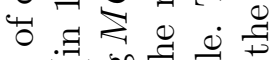
刍 节

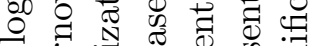
폴

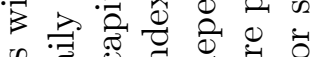

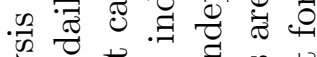

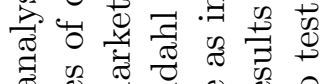
శี శี

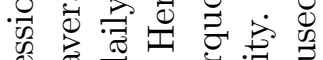
व

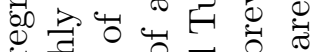

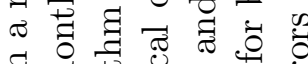
‡્व ๑ 0 రై

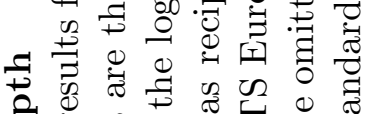

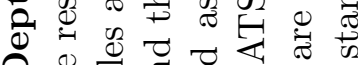
ด

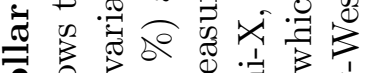
ค

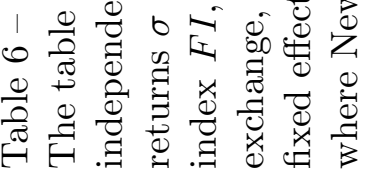
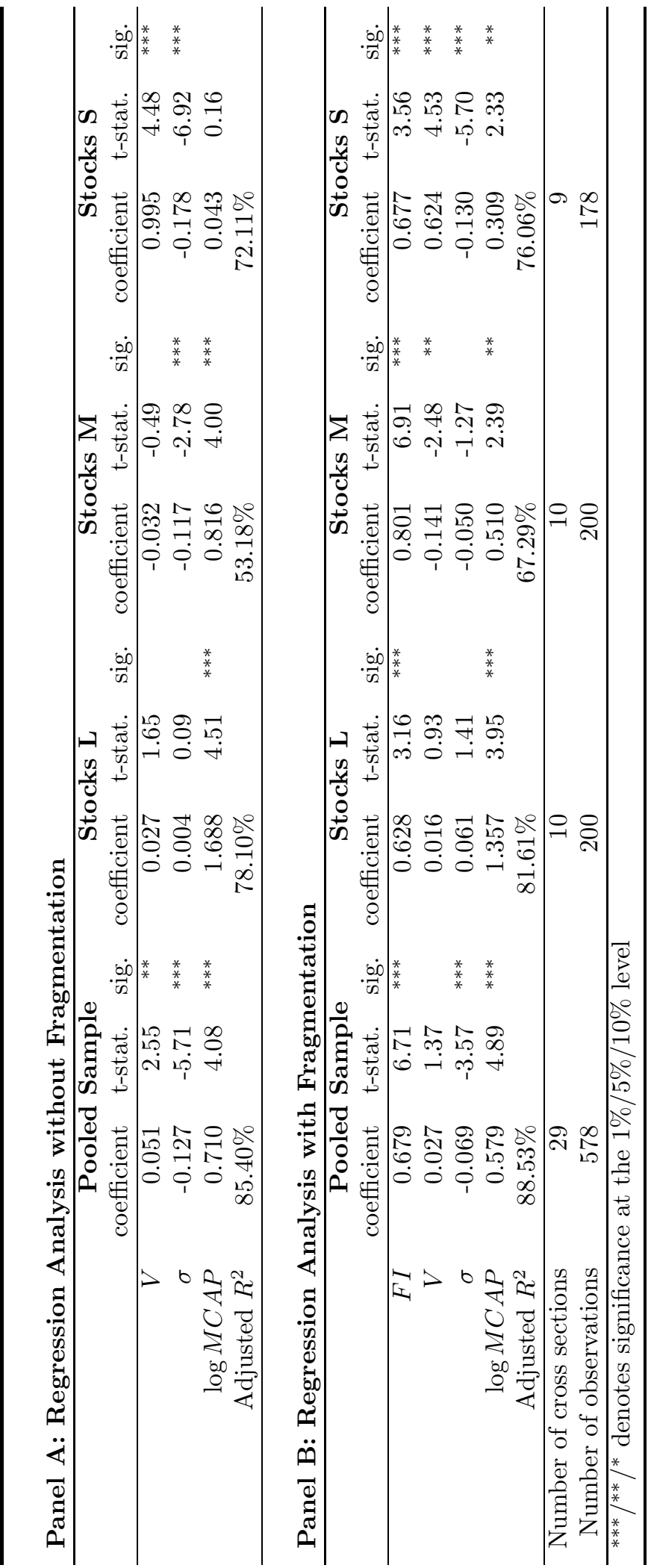


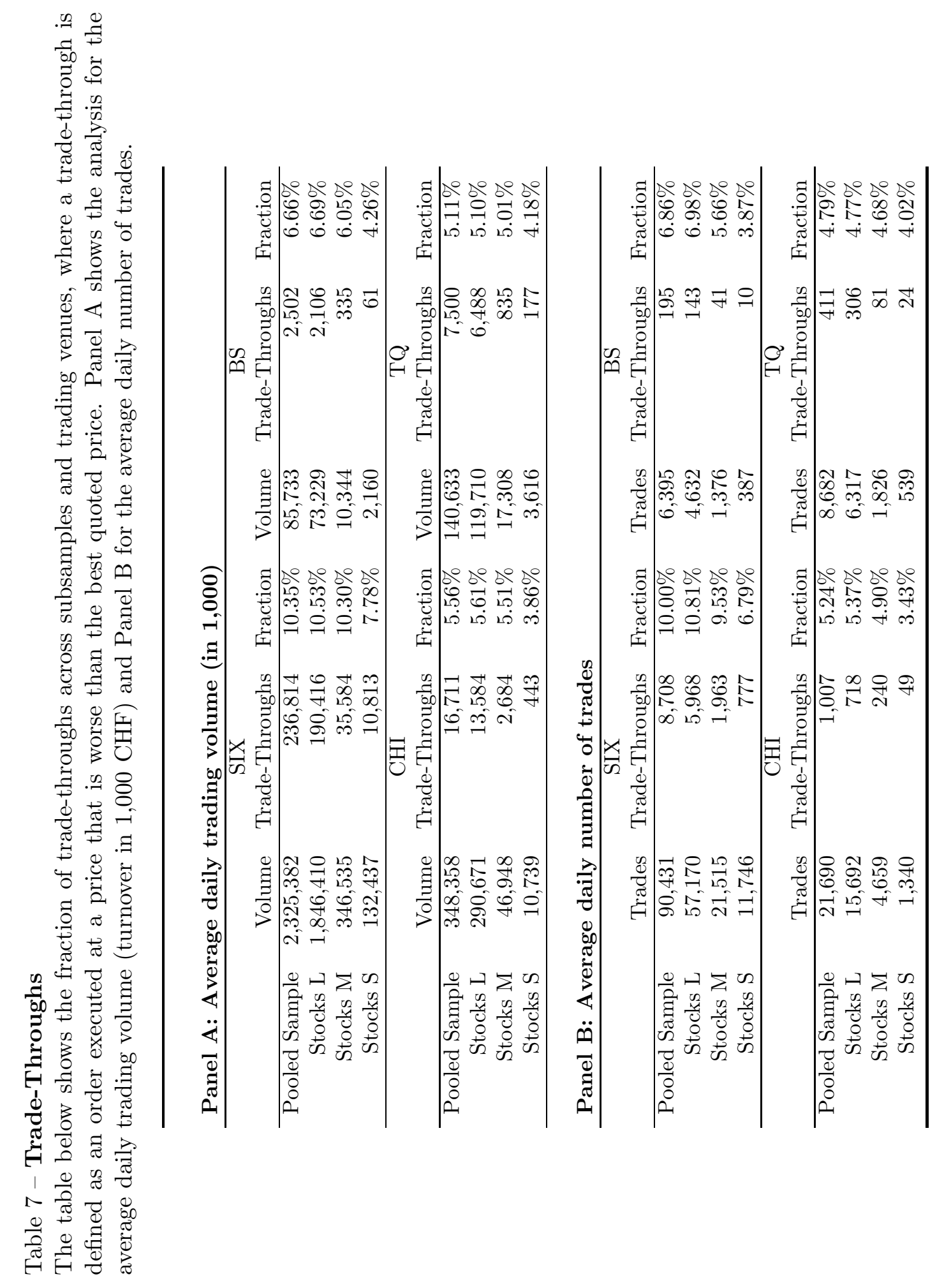




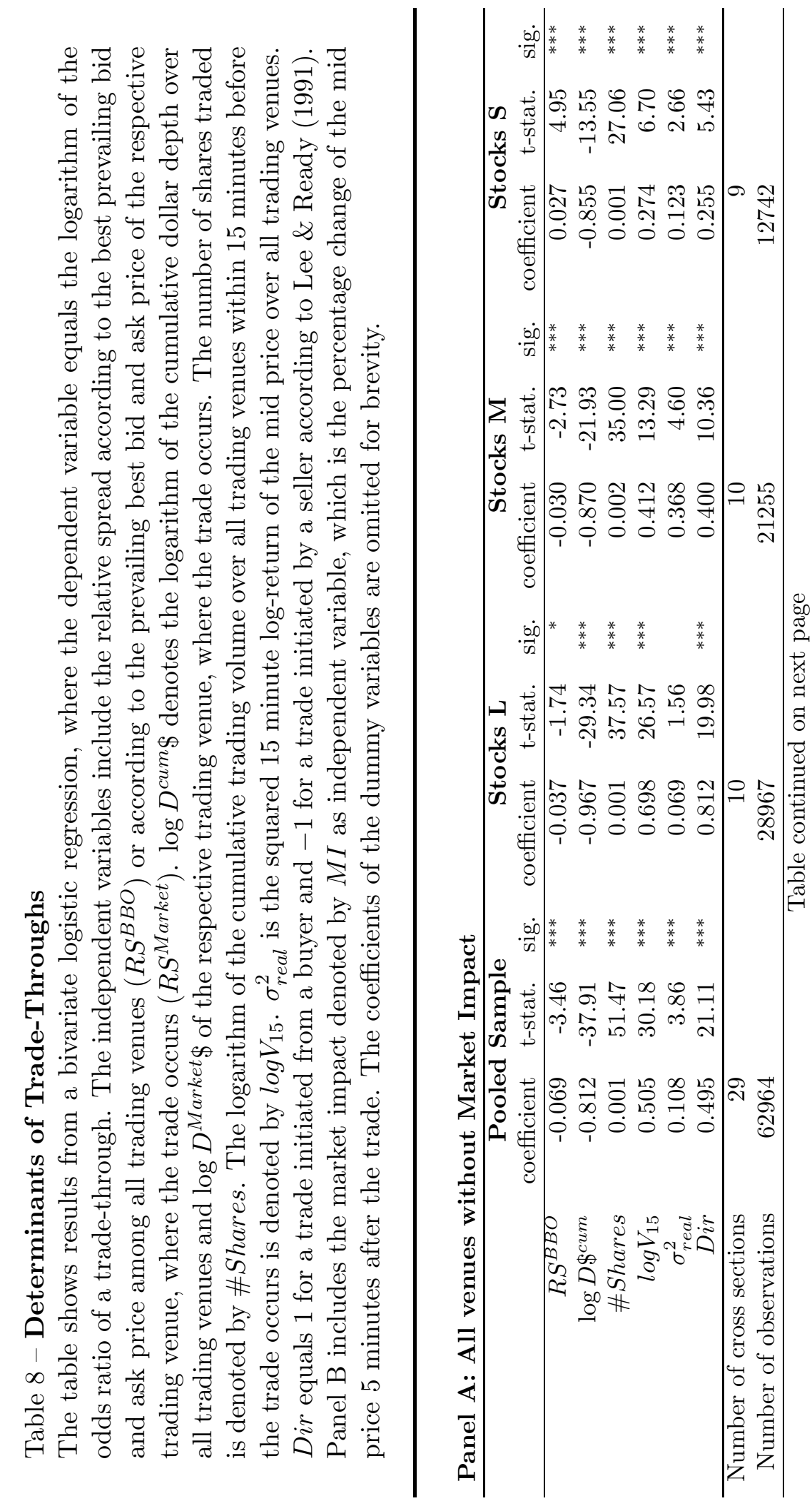



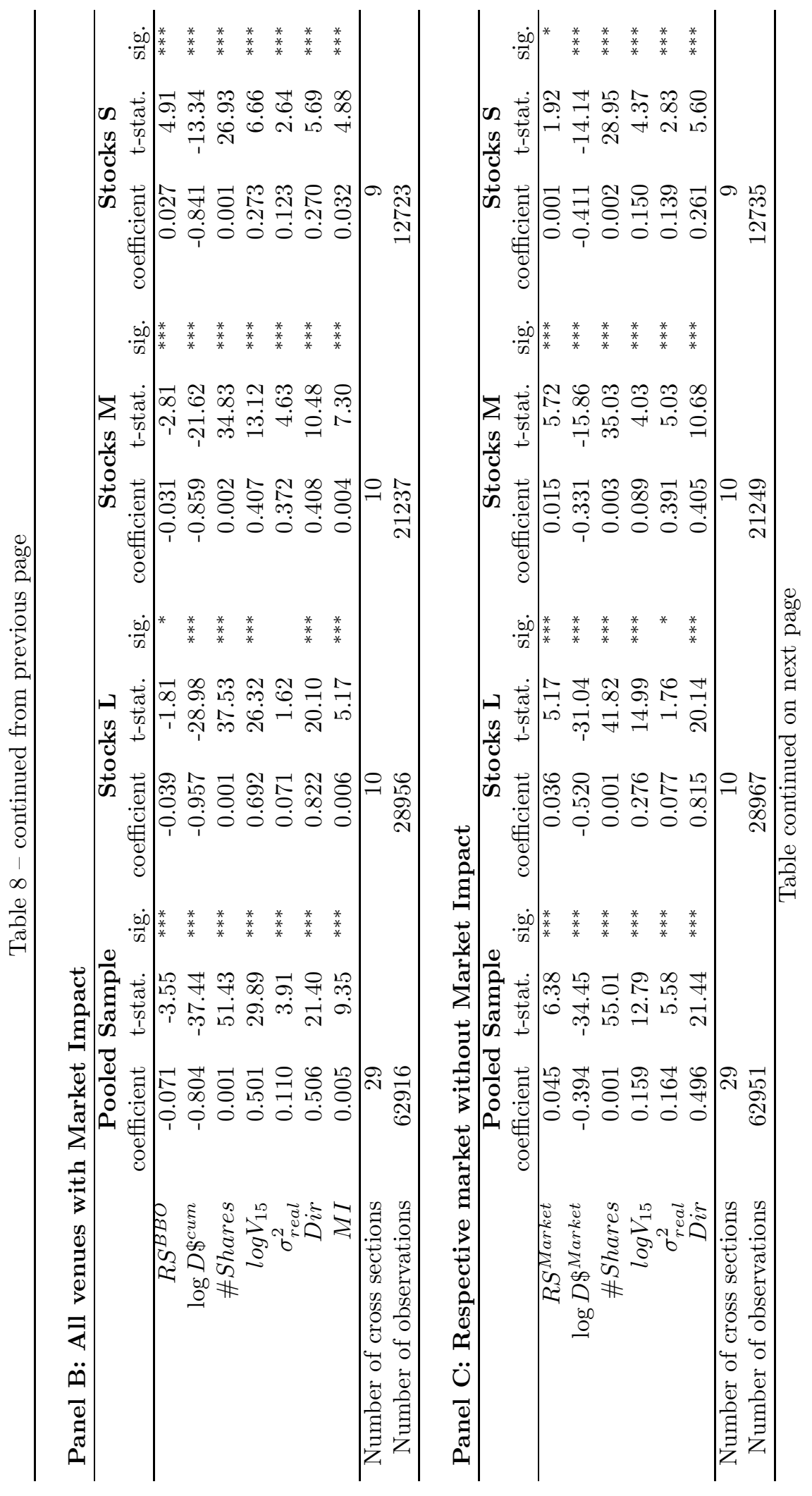


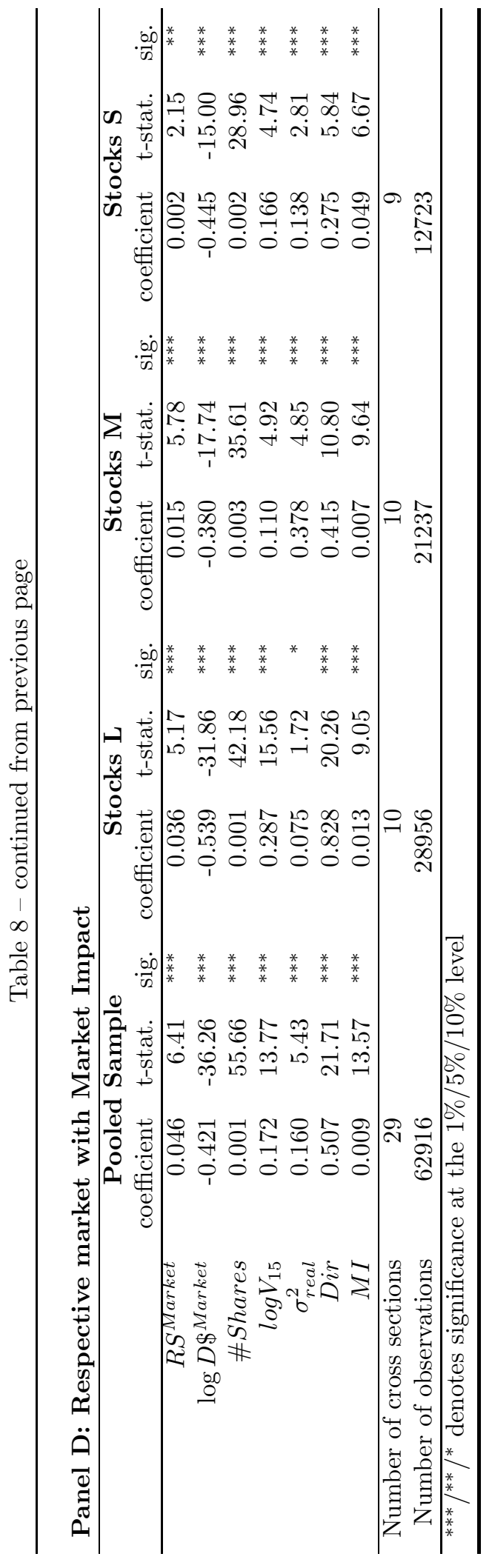




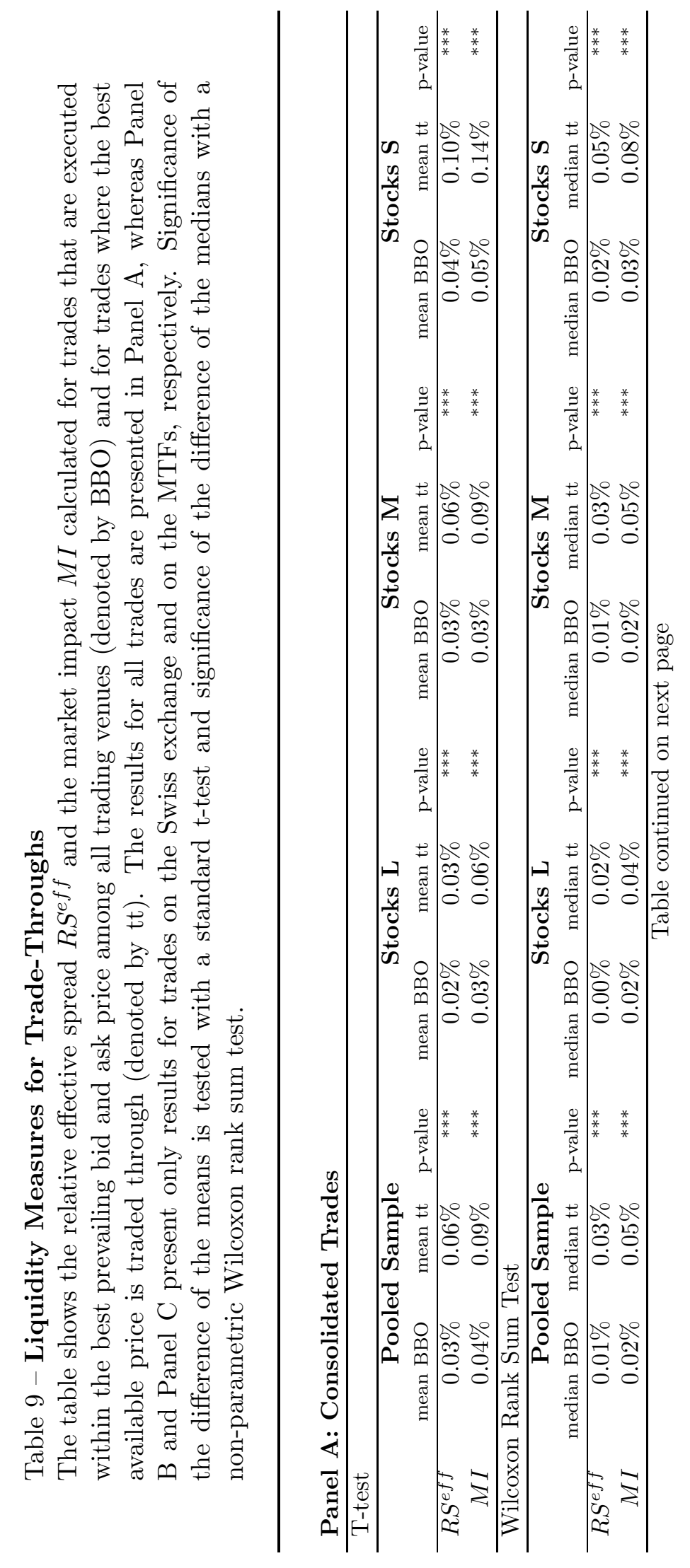




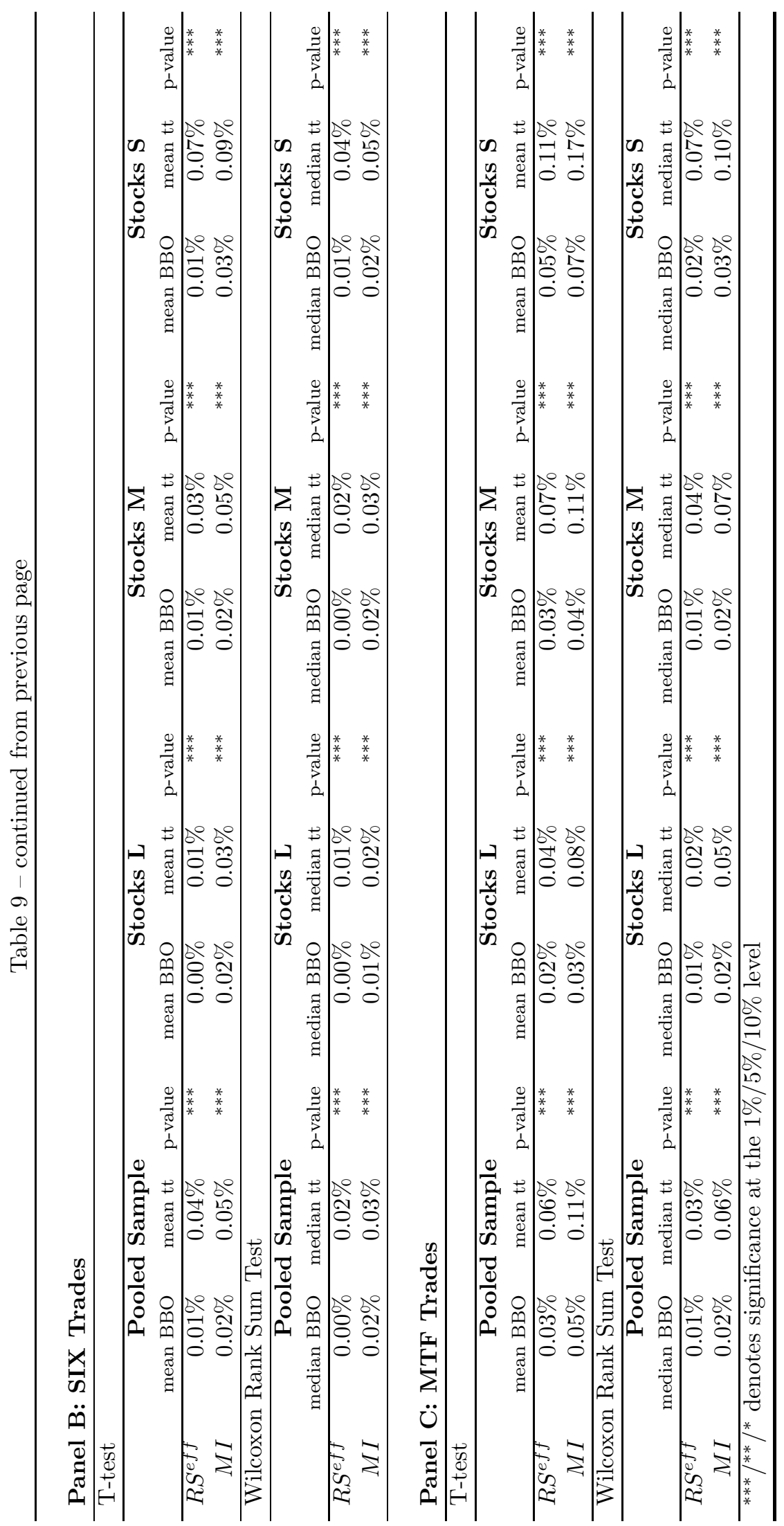




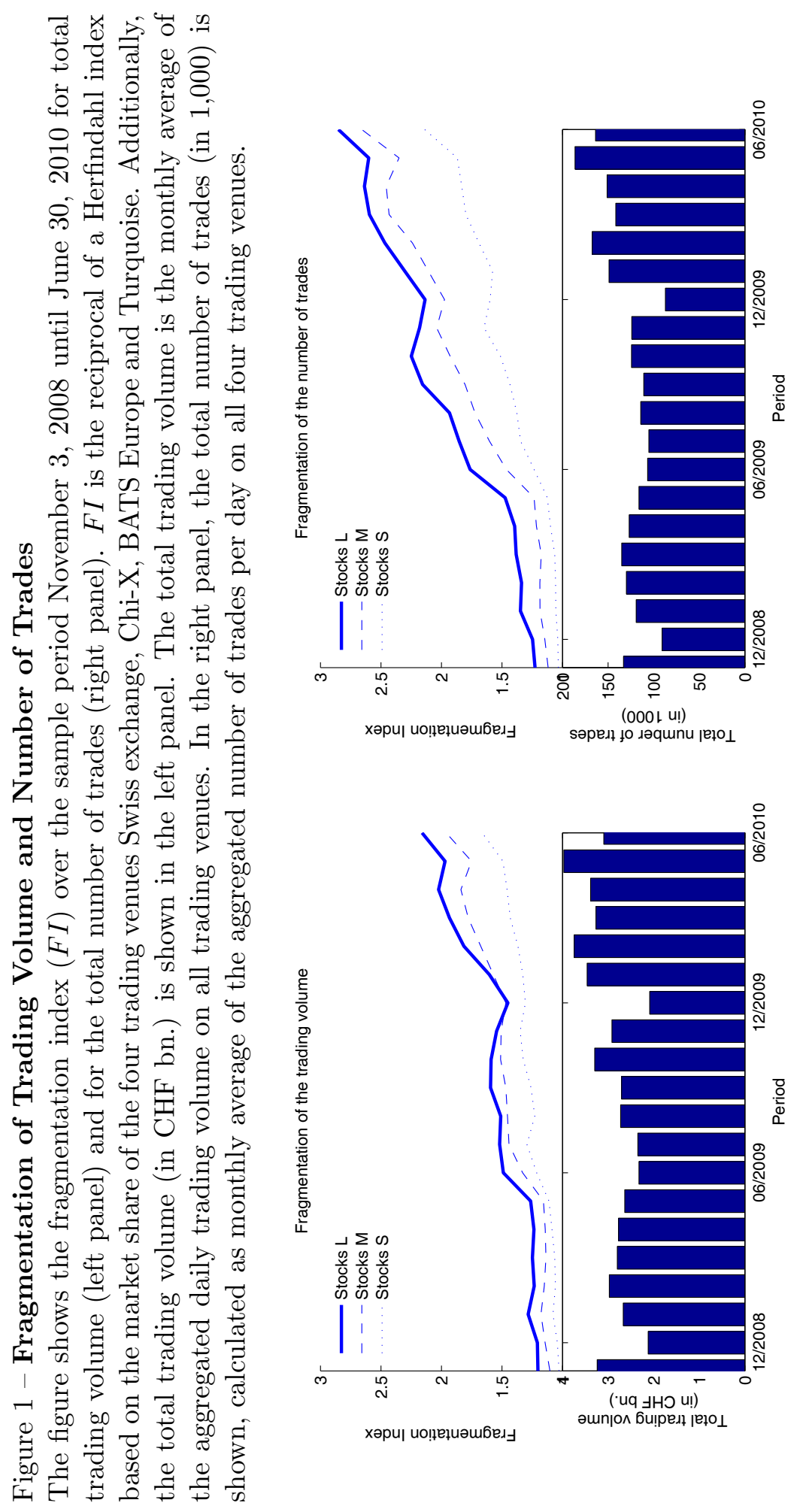




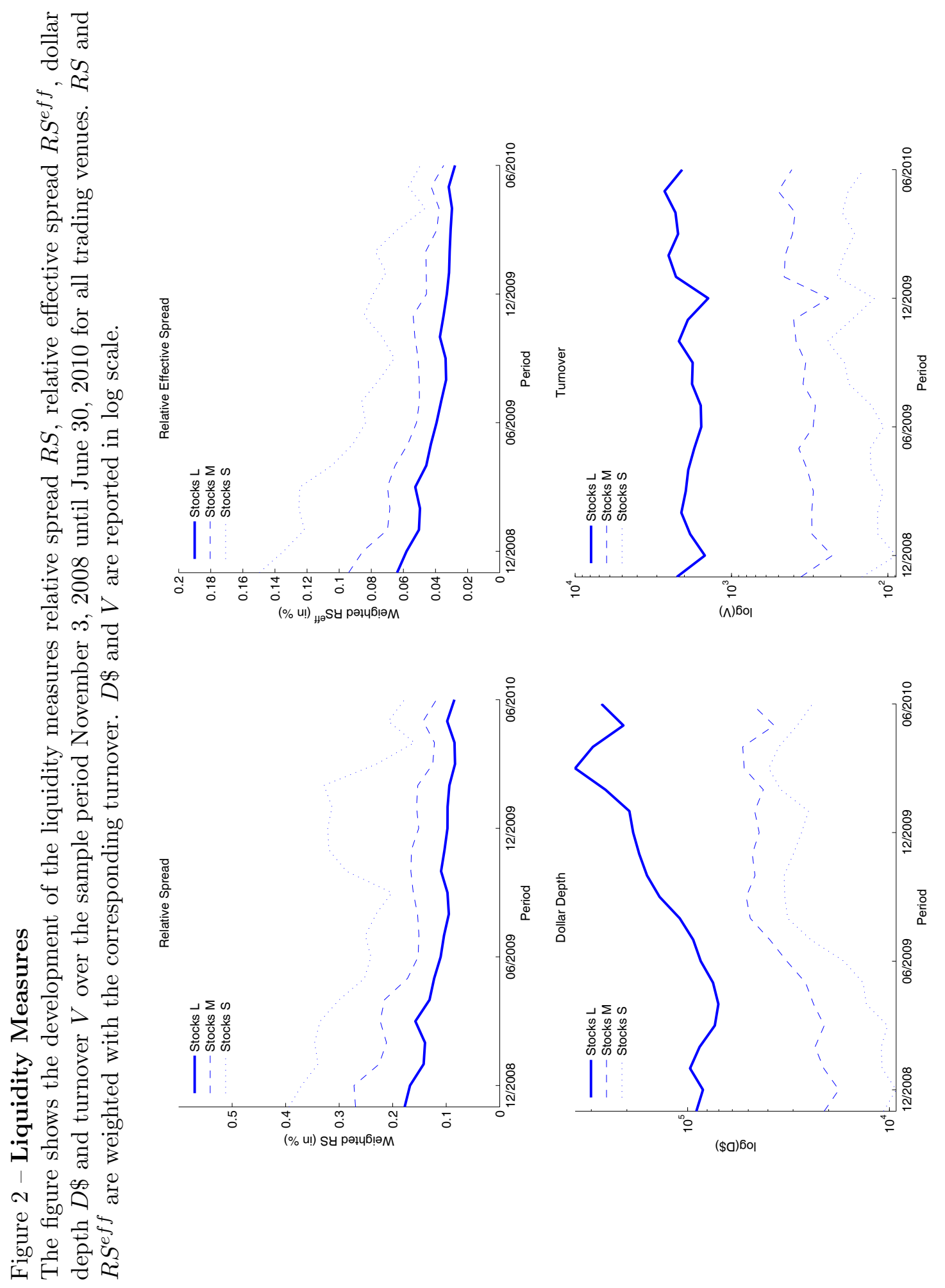

